Conclusions Most patients had grade 3-4 liver fibrosis. Most patients were recurrent or non-responders to previous treatment. Telaprevir was the most used protease inhibitor.

Patients using telaprevir got negative viral loads before patients using boceprevir.

A high percentage of patients using boceprevir required the dose of peginterferon-alfa to be reduced and treatment with G-CSF due to neutropenia.

No conflict of interest.

\section{DGI-056 REDUCED DELAY IN THE ADMINISTRATION OF CHEMOTHERAPY AFTER OPTIMISING THE PROCESS OF PREPARATION/DISPENSING OF PARENTERAL ANTINEOPLASTICS}

doi:10.1136/ejhpharm-2013-000276.322

C Borrell, MJ Esteban, J Ruiz, JE Megías, E López, ' JL Poveda. Hospital Universitario La Fe, Pharmacy, Valencia, Spain

Background Separation between the Chemotherapy Unit and the Day Hospital Unit makes rapid treatment of onco-hematologic patients difficult.

Purpose To optimise the sequence of dispensing parenteral antineoplastic mixtures when there is relevant physical separation between the Chemotherapy Unit (CU) of the Pharmacy Department and the Day Hospital Unit (DHU) where these treatments are administered to onco-hematologic patients.

Materials and Methods We reviewed stability data from mixtures of antineoplastics, each from Pharmacotherapeutic Schemes (PS) and updated the protocol in our Oncofarm programme. To plan the appointments of onco-haematological patients in the DHU, patients were grouped into three types depending on the stability of the mixtures and the total time of administration: type I [analysis $(\mathrm{A})$, cheque $(\mathrm{V})$ administration and chemotherapy (CT) on the same day], type II (A: one day, with $\mathrm{V}$ and CT the next day) and type III (A and V one day, with CT the next day). To evaluate the efficiency of the process, the compliance productivity indicator 'lag time' between confirming the treatments prescribed by doctors and the start of their administration in DHU was calculated.

Results With support from various literature sources, we reviewed the stability of 54 antineoplastic mixtures and updated the Oncofarm data. Of 482 PS analysed, 30\% would be appropriate for type I patients, $2 \%$ for type II and $68 \%$ for type III. The new stability data allowed us to prepare a total of 28 new PS in the CU the day before their administration. To gauge productivity the 'lag time' was calculated for a period of three months for treatments prescribed electronically to 552 patients and the 1023 mixtures dispensed to DHU. The average delay was 2:23 ( $\mathrm{SD}=0: 37$ ) hours, keeping the level of compliance at $100 \%$.

Conclusions The reorganisation of the antineoplastic preparation process based on the updated stability data made it possible to dispense the mixtures of PS prescribed for type II and III patients at the best time. This ensured optimum services to health professionals and patient satisfaction.

No conflict of interest.

\section{DGI-057 RELATIONSHIP BETWEEN IN-HOSPITAL USE OF ANTIPSEUDOMONAL AGENTS AND RESISTANCE TO CARBAPENEMS FOR PSEUDOMONAS AERUGINOSA IN A GENERAL HOSPITAL OVER A NINE-YEAR PERIOD}

doi:10.1136/ejhpharm-2013-000276.323

M Saez-Villafañe, I Yañez-Gonzalez, E Gutierrez-Gutierrez, C Prieto-Fernandez, JJ Ortiz De Urbina, L Ortega-Valin, M Noguerol-Cal, C Rodriguez-Lage. Complejo Asistencial De Leon, Pharmacy, Leon, Spain
Background Antimicrobial resistance is frequently related to the high selective pressure of antimicrobials commonly used in hospitalised patients.

Purpose To analyse in-hospital consumption of antipseudomonal agents (AAC), trends and the relationship with increase in Pseudomonas aeruginosa (PA) resistant to imipenem or meropenem.

Materials and Methods Descriptive retrospective analysis (20022010) of the AAC in a 1,100-bed tertiary teaching hospital. Data on the use of antibiotics were obtained from the hospital pharmacy and expressed as defined daily doses per 100 bed-days (DDD/100 bed-days).

Resistance rates were obtained from Microbiology and expressed as percentage of total PA cultures resistant to imipenem or meropenem.

Pearson's correlation coefficient(r) was used to determinate the relationship between $\mathrm{AAC}$ and \% PA resistant to imipenem or meropenem. Linear regression analysis was used to further analyse these relationships with $r \geq 0.7$

Results Antipseudomonal agents represented $20.44 \%$ of all antibiotics in 2002 and $28.86 \%$ in 2010 .

The relationship was studied between each AAC (2002-2010) and \%PA resistant to imipenem or meropenem, and a positive relationship ( $r>0.7$ ) was observed between the increase in P/T, MER, IMI and LEV consumption and increase in \%PA resistant to meropenem. Linear regression analysis was used for these antibiotics. The strongest relationship was observed between levofloxacin and \%PA resistant to meropenem $\left(\mathrm{r}^{2}=0.7970\right)$. Coefficients of determination $\left(\mathrm{r}^{2}\right)$ for $\mathrm{P} / \mathrm{T}$, IMI and MER were 0.6951, 0.5932 and 0.5313 respectively.

Conclusions During the period studied, the trend was for an overall increase in antibiotics consumption, in the use of antipseudomonal agents (principally piperacillin-tazobactam and levofloxacin), in the number of cases of PA and in resistances rates (mainly to meropenem).

Data suggest that increasing use of $\mathrm{P} / \mathrm{T}$, imipenem, meropenem and especially levofloxacin, means an increase in \%PA resistant to meropenem.

Antibiotic consumption is important to explain trend in resistance rates, but other variables may also be involved, so we must to be prudent interpreting these types of studies. Despite the limits, more exhaustive studies may be done to determinate the relationship between antibiotics consumption and resistance rates.

\section{Abstract DGI-057 Table 1}

\begin{tabular}{|c|c|c|c|c|c|c|c|c|c|}
\hline & 2002 & 2003 & 2004 & 2005 & 2006 & 2007 & 2008 & 2009 & 2010 \\
\hline $\begin{array}{l}\text { Piperacillin- } \\
\text { Tazobactam (P/T) }\end{array}$ & 0.76 & 0.83 & 1.30 & 1.95 & 2.36 & 3.22 & 3.82 & 3.68 & 4.29 \\
\hline Ceftazidime & 0.95 & 0.66 & 0.69 & 0.70 & 0.59 & 0.59 & 0.63 & 0.56 & 0.69 \\
\hline Cefepime & 0.62 & 0.72 & 0.93 & 1.16 & 1.05 & 0.76 & 0.98 & 1.05 & 0.94 \\
\hline Meropenem (MER) & 0.68 & 0.47 & 0.49 & 0.47 & 0.42 & 0.51 & 0.90 & 0.81 & 1.03 \\
\hline Imipenem (IMI) & 1.14 & 0.99 & 1.18 & 0.94 & 0.86 & 1.39 & 1.30 & 1.43 & 1.43 \\
\hline Ciprofloxacin & 6.25 & 5.31 & 5.07 & 5.73 & 5.67 & 6.14 & 6.02 & 5.91 & 5.98 \\
\hline Levofloxacin (LEV) & 1.79 & 1.94 & 2.03 & 2.79 & 3.52 & 6.96 & 6.73 & 6.63 & 6.83 \\
\hline $\begin{array}{l}\text { Overall antibiotics } \\
\text { (ATC J01) }\end{array}$ & 59.63 & 50.98 & 51.55 & 56.86 & 55.77 & 69.02 & 74.18 & 70.84 & 73.43 \\
\hline $\begin{array}{l}\text { Number of cases } \\
\text { of PA (N) }\end{array}$ & 534 & 506 & 718 & 749 & 774 & 1126 & 1280 & 1250 & $\begin{array}{l}\text { Not } \\
\text { available }\end{array}$ \\
\hline $\begin{array}{l}\text { \%PA resistant to } \\
\text { imipenem }\end{array}$ & 12.90 & 14.70 & 15.60 & 15.60 & 11.70 & 14.10 & 14.70 & 11.40 & 14.20 \\
\hline $\begin{array}{l}\text { \%PA resistant to } \\
\text { meropenem }\end{array}$ & 7.40 & 6.70 & 6.50 & 7.70 & 6.30 & 11.30 & 12.70 & 9.30 & 11.40 \\
\hline
\end{tabular}

No conflict of interest. 